\title{
Tree cover and diversity modulate the response of carbon storage to precipitation variability in an Indian semi-arid forest
}

\author{
Nirav Mehta ${ }^{1}$, Sergio Sanchez ${ }^{2}$, Prashanth Marpu $^{2}$, Ankur R. Desai ${ }^{3}$ and \\ N. S. R. Krishnayya ${ }^{1, *}$ \\ ${ }^{1}$ Ecology Laboratory, Department of Botany, Faculty of Science, The Maharaja Sayajirao University of Baroda, Vadodara 390 002, India \\ ${ }^{2}$ Institute Center for Water and Environment (iWATER), Masdar Institute of Science and Technology, PO Box 54224, Abu Dhabi, \\ United Arab Emirates \\ ${ }^{3}$ University of Wisconsin-Madison, Department of Atmospheric and Oceanic Sciences, 1225 W Dayton St, AOSS 1549, Madison, WI 53706, USA
}

\begin{abstract}
Water availability is the central limiting factor for vegetation carbon allocation in semi-arid forests. However, the sensitivity of this relationship likely varies as a function of total tree cover and tree diversity. In the present study, a set of re-measured semiarid forest plots in India were analysed to test how sensitive biomass, productivity and soil organic carbon (SOC) accumulation were to variability in precipitation from plot-level and remote sensing solarinduced fluorescence (SIF) measurements. Variability in mean precipitation at zones I and II impacted tree density, recorded as 150 and 400 trees ha $\mathrm{h}^{-1}$ respectively. Results show that low tree cover plots had lower woody biomass NPP (NPP wood) and lower SIF sensitivity to inter-annual variation of precipitation. Increment in NPP wood over a five-year period was significantly smaller $(P<0.05)$ in zone I $\left(0.21 \mathrm{Mg} \mathrm{ha}^{-}\right.$ ${ }^{1}$ year $^{-1}$, CI95, 0.14-0.28) than at zone II $\left(2.44 \mathrm{Mg} \mathrm{ha}^{-}\right.$ ${ }^{1}$ year $^{-1}$, CI95, 1.43-3.45). Mean annual SOC increment at $0-5 \mathrm{~cm}$ depth varied between 0.13 and $0.75 \mathrm{Mg} \mathrm{ha}^{-}$ ${ }^{1}$ year $^{-1}$ across the study area. Results highlight the importance of tree cover diversity in modulating the response of semi-arid forests to carbon storage across a precipitation gradient.
\end{abstract}

Keywords: Annual rainfall, carbon storage, precipitation variability, semi-arid forest, tree cover and diversity.

SEMI-ARID regions constitute around $15 \%$ of global land area and show significant inter- and intra-annual variability in precipitation that influences net carbon uptake, and also the magnitude and trajectory of the global land biosphere carbon sink ${ }^{1}$. Further, recent climate change has led to increasingly dry conditions during the dry season ${ }^{2}$. These changes are likely to have a serious impact on the growth and mortality of trees in semi-arid forests ${ }^{3,4}$.

While forest density, diversity and productivity have all been linked to annual rainfall variation ${ }^{3-5}$, and dryland aridity $^{6}$, large uncertainty exists in forest growth esti-

*For correspondence. (e-mail: krish14@gmail.com) mates of developing countries ${ }^{5}$, such as India, and especially for semi-arid tropical forests which tend to have high species diversity and varied productivity. A potential mitigating factor of semi-arid forests to drought response may be tree species diversity and shifts in allocation of carbon to wood ${ }^{7,8}$. In a study over two decades of drought $^{8}$, drought-tolerant species were found to be favoured in conjunction with an increase in forest biomass. Niche efficiency theory predicts that individual plant productivity diminishes under biodiversity loss with an increasing rate ${ }^{5}$. Thus, we hypothesize that variations in species diversity across these forests lead to high variation in forest productivity responses to precipitation variability.

We carried out a ground-based tree-by-tree assessment on the impact of rainfall dynamics of a semi-arid region on tree cover using a set of remeasured values of biomass, soil organic carbon (SOC) and tree mortality over a five-year timescale. Chlorophyll solar-induced fluorescence (SIF) is a potential pathway to map photosynthetic production across time and space ${ }^{9,10}$. Thus, we also carried out analyses to determine whether SIF can be linked with our plot-based study to evaluate drought sensitivity across space and time. Specifically, in a semi-arid tropical forest we tested the correlation between spatial variation of rainfall, above-ground tree biomass and SOC (H1), and whether this variation was modulated by species diversity or mean fraction tree cover (H2). We also assessed whether temporal variation in SIF correlates with plot-level relationships (H3) and thus provides a means for extrapolating these responses across space.

\section{Methods}

\section{Study area}

The study region is located in Gujarat, India, lying between $20^{\circ} 07^{\prime}$ and $24^{\circ} 41^{\prime} \mathrm{N}$ and $68^{\circ} 10^{\prime}$ and $74^{\circ} 28^{\prime} \mathrm{E}$ in a semi-arid tropical forest. Monthly minimum and maximum temperatures ranged between $2^{\circ} \mathrm{C}$ and $15^{\circ} \mathrm{C}$ as well as $38^{\circ} \mathrm{C}$ and $45^{\circ} \mathrm{C}$. Annual rainfall occurred almost entirely 
during the monsoon period from mid June to October (India Meteorological Department (IMD), Government of India (GoI); http://www.imd.gov.in). Site data were collected as part of a two-phase study of the national vegetation carbon pool assessment carried out by the Indian Space Research Organisation under the International Geosphere Biosphere Programme. Phase I of the field study was carried out between 2008 and 2009, while Phase II between 2013 and 2014 , leading to a five-year remeasurement interval. The five-year timescale matches with the measurement strategy of CTFS-ForestGEO sites (http://www.forestgeo.si.edu/) for characterizing forest structure, biodiversity and growth dynamics over larger spatial areas.

The study area was divided into two distinct rainfall zones: zone I with a five-year mean rainfall of $684 \mathrm{~mm}$ (range: $300-1155 \mathrm{~mm}$ ) and zone II with $1085 \mathrm{~mm}$ (717$1413 \mathrm{~mm}$ ). The spread of study plots and rainfall gradation across the study area (includes the two zones) are given in Supplementary Figures 1, $2 a$ and $b$. Rainfall data show gradation of rainfall across the zones. These data were derived from satellite-based data of Tropical Rainfall Measuring Mission (TRMM; https://pmm.nasa.gov/trmm). Mean annual rainfall data were obtained from IMD, GoI data (Supplementary Figure $2 a$ and $b$ ). During the phase I study, the percentage of young trees (diameter at breast height (DBH) 3-4 cm) was in the range of 5-10 across the study plots. Young tree numbers at both the zones were similar. Older trees with higher DBH $(13-19 \mathrm{~cm})$ were found to be relatively higher in zone II (ref. 11). In both zones, most of the tree diversity was natural, the exceptions being some commercially important species such as Dendrocalamus strictus Nees (bamboo) and Madhuca indica J. F. Gmel. (mahuda). Locals and state Forest Department encourage plantation of these species. Two important timberyielding trees, viz. Tectona grandis L. f. (teak) and Acacia catechu Willd. (khair) are periodically planted by the state Forest Department to replenish harvested trees.

\section{Field sampling}

Mehta et al. ${ }^{11}$ have provided detailed description of sample plot layout, methodology of sampling for aboveground biomass and SOC estimation. Briefly, 95 $250 \times 250 \mathrm{~m}$ (6.25 ha) plots were distributed with 61 in zone I and 34 in zone II, totalling 593.75 ha of sampled area. Based on NDVI (normalized difference vegetation index) values, each sample plot was then subdivided into four quadrats of $30 \times 30 \mathrm{~m}$, with one quadrat marked for long-term monitoring (Supplementary Material). The distribution and dimensions of trees of the other three quadrats were selected to match those of the long-term monitored quadrat with no less than $75 \%$ similarity. Additional details of the sampling protocol are given in the Supplementary Material.

Trees $(>4 \mathrm{~cm} \mathrm{DBH}$ at $1.37 \mathrm{~m}$ from the ground level) growing in one of these quadrats were tagged in phase I for monitoring mass increment over the five-year timescale. Sampled plots of the original phase I study were located using GPS coordinates and revisited after five years. During the second visit, changes were noted in vegetation cover by recounting tree number and diversity of each quadrat. Biophysical dimensions of tagged trees, addition or deletion of tree species along with tree count variation were recorded (Supplementary Figure $3 a$ and $b$ ). In addition to tree species inventorying, soil samples were collected to check whether there was any change in SOC. Soils were sampled within a $15 \mathrm{~m}^{2}$ range of locations carried out in phase I. Fallen litter was removed and soil cores were obtained using a gouge auger.

\section{Above-ground biomass estimation}

Above-ground biomass of tree cover was estimated using the pantropical allometric equation model-4 given by Chave et al. ${ }^{12}$, an improvement over the original phase I above-ground biomass estimation made from the model of Chave et al. ${ }^{13}$. Foliage biomass was not included in these calculations. Above-ground biomass of phase I was recalculated using this new equation for comparability ${ }^{12}$. Recalculated phase-I values were considered as baseline above-ground wood biomass values, and were used to record change in wood biomass over the five-year timescale. The difference in values between phase II and phase I was used as an estimate of change, if any, in above-ground biomass over the five-year timescale.

To convert biomass change to net primary productivity (NPP) wood density for the tree species was obtained from Food and Agriculture Organization of the United Nations (FAO) ${ }^{14}$ and Indian Institute of Remote Sensing (IIRS), Dehradun. Difference in these dry wood biomass values between phase I and phase II was considered as mass increment/decrement in the five-year timescale. After dividing these values by 5, dry wood biomass values were expressed as $\mathrm{NPP}_{\text {wood }}$ (net primary production of wood, $\mathrm{Mg} \mathrm{ha}^{-1} \mathrm{year}^{-1}$ ).

\section{Estimation of soil organic carbon}

SOC in $50 \%$ of the collected soil samples was estimated by wet oxidation method ${ }^{15}$. Three cores were extracted and a composite sample was made by mixing soils of $0-5$ depth and $10-15 \mathrm{~cm}$ independently. Samples were air-dried, and fine roots and broken litter were removed. The remaining material was passed through a $0.5 \mathrm{~mm}$ sieve. SOC analysis for each sample was carried out in triplicate. Mean values $\left(\mathrm{Mg} \mathrm{C} \mathrm{ha}^{-1}\right)$ were obtained for sampled quadrats. SOC values of phase I and phase II were compared and divided by 5 to obtain SOC $\left(\mathrm{mg} \mathrm{ha}^{-1}\right.$ year $\left.^{-1}\right)$. 
RESEARCH ARTICLES
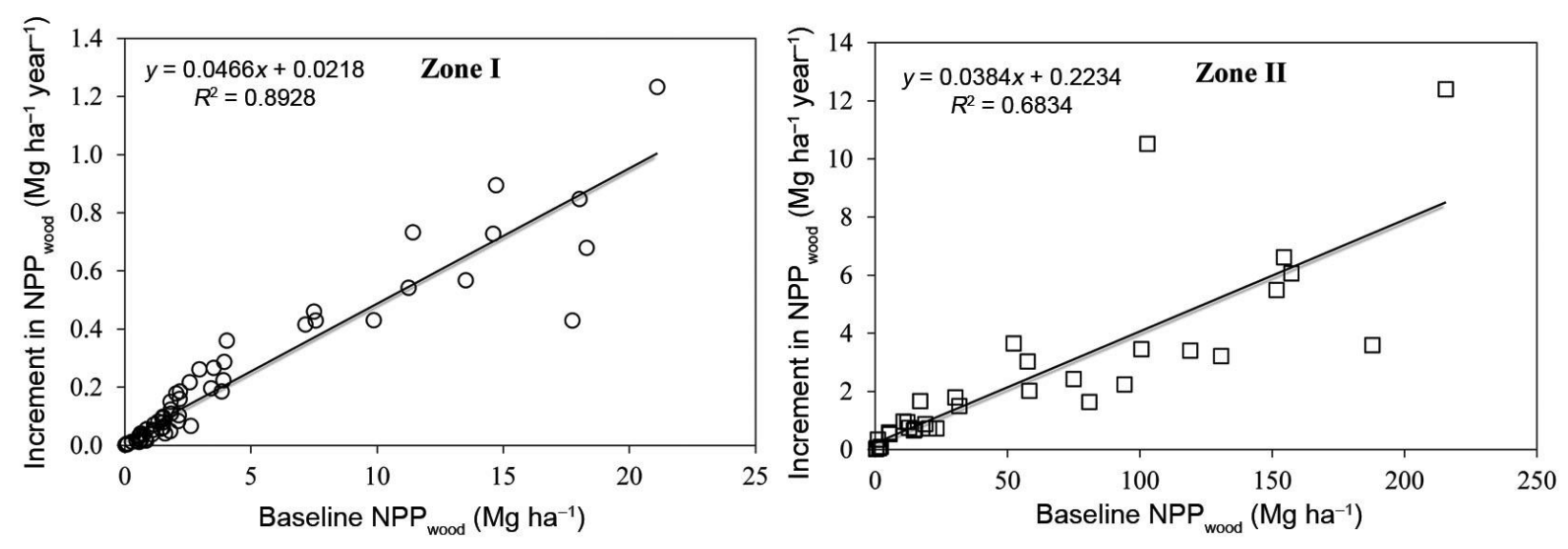

Figure 1. Relationship between baseline net primary production of wood biomass $\left(\mathrm{NPP}_{\text {wood }}, \mathrm{Mg} \mathrm{ha}^{-1} ; 2009-10\right)$ and increment in NPP ${ }_{\text {wood }}$ after a five-year timescale (zone I: 61 plots, zone II: 34 plots).

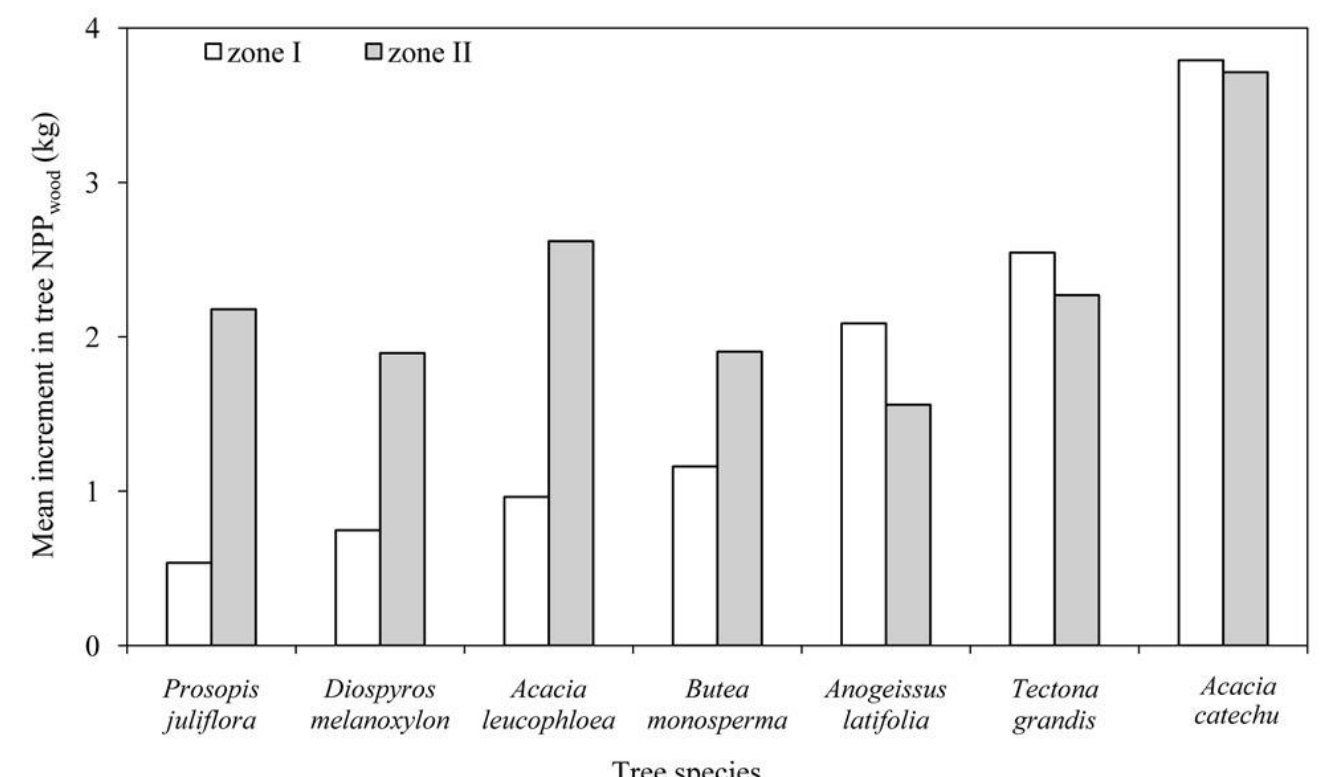

Figure 2. Mean increment in $\mathrm{NPP}_{\text {wood }}\left(\mathrm{kg} \mathrm{tree}^{-1}\right.$ year $^{-1}$, after a five-year timescale) amongst common species to each zone.

\section{Solar-induced fluorescence data}

Gridded SIF data from GOME-2 instrument on-board the MetOp-A platform were extracted from http://www.gfzpotsdam.de/en/section/remote-sensing/projects/globfluo/ data/. Monthly mean SIF radiance $\left(\mathrm{mW} \mathrm{m}^{-2} \mathrm{~nm}^{-1} \mathrm{Sr}^{-1}\right)$ for each pixel of $40 \times 80 \mathrm{~km}$ size was extracted for both the zones for the period 2009-2014, coinciding with the timing of field-data generation. Pixels showing negative values, zero or missing values were discarded during data processing. SIF values were subsequently temporally aggregated to align and correlate them to monthly mean precipitation. To evaluate SIF against traditional global satellite NPP estimates, monthly mean NPP was extracted from NASA Terra/MODIS MOD17A2 at $1 \mathrm{sq} . \mathrm{km}$ spatial resolution.

\section{Data analysis}

The number of tree species present and the density of trees for each species in all quadrats in both the zones were used to calculate Shannon diversity index. One-way ANOVA was carried out using SPSS software to check whether the differences seen in the measured parameters are significant or not. Pairwise linear regression between tree mass and mass increment, SIF and precipitation, SIF and NPP (of MOD17A2), mass increment and SOC increment were analysed in MATLAB to evaluate the relationship between rainfall and tree species diversity on the measured parameters. Normal probability plots of the residuals were developed in MATLAB to the linear regression model to check error distribution. Significance testing of observed parameters between zone I and 
zone II was conducted using Student's $t$-test in MATLAB.

\section{Results}

\section{Precipitation spatial variability and its impact on $N P P_{\text {wood }}$ and $S O C$}

The two zones had distinctive mean annual precipitation with large within-zone variation. The mean five-year rainfall was significantly $(P<0.05)$ lower in zone I compared to zone II (Supplementary Figure 2). Zone I also experienced higher interannual fluctuations ranging between $-56 \%$ and $69 \%$ of the five-year mean, while deviations were lesser in zone II ( $-34 \%$ to $30 \%)$.

Results indicate that difference in precipitation has impacted tree density (Supplementary Tables 1 and 2), and higher tree density augmented productivity. Mean tree density in zone I and zone II was 150 and 400 trees ha ${ }^{-1}$ respectively. Mean $\mathrm{NPP}_{\text {wood }}$ in the baseline year (2009) was $0.81 \mathrm{Mg} \mathrm{ha}^{-1}\left(\mathrm{CI}_{95}, 0.53-1.08\right)$ in zone $\mathrm{I}$ and $11.54 \mathrm{Mg} \mathrm{ha}^{-1}\left(\mathrm{CI}_{95}, 7.21-15.87\right)$ in the wetter zone II. Similarly, increment in $\mathrm{NPP}_{\text {wood }}$ was significantly smaller $(P<0.05)$ in zone I $\left(0.21 \mathrm{Mg} \mathrm{ha}^{-1}\right.$ year $^{-1}, \mathrm{CI}_{95}, 0.14$ $0.28)$ than in zone II $\left(2.44 \mathrm{Mg} \mathrm{ha}^{-1}\right.$ year $^{-1}, \mathrm{CI}_{95}, 1.43$ 3.45) (Figure 1, Supplementary Figure 4). Approximately $2-3 \%$ of tagged trees were lost, and based on the markings observed on trunk, it could be likely due to tree felling for timber or firewood.

Across different tree species of the region in both zones, some species showed greater increment in $\mathrm{DBH}$ (by $15-45 \%$ ), while others tended to increase primarily in height (by 18-32\%), showing a species-dependent response (Supplementary Figures 5 and 6). As a result, the relationship of $\mathrm{NPP}_{\text {wood }}$ increment $\left(\mathrm{Mg} \mathrm{ha}^{-1}\right.$ year $\left.^{-1}\right)$ to baseline tree mass was found to have a break-point in the linear regression (Supplementary Figure 7). None of the recorded species showed a declining trend in the increment of $\mathrm{NPP}_{\text {wood. }}$

SOC changes were subtler than those of $\mathrm{NPP}_{\text {wood. }}$ The baseline SOC recorded in 2009 and increment analysis carried out in 2014 (Supplementary Table 3) showed mean annual SOC increment at $0-5 \mathrm{~cm}$ depth of $0.18 \mathrm{Mg} \mathrm{ha}^{-1}$ year $^{-1}\left(\mathrm{CI}_{95}, 0.13-0.23\right)$ in zone I and $0.55 \mathrm{Mg} \mathrm{ha}^{-1}$ year $^{-1}\left(\mathrm{CI}_{95}, 0.36-0.75\right)$ in zone II. In zone II, increment in SOC was found at $10-15 \mathrm{~cm}$ soil depth in addition to shallow soil, an effect not observed in zone I, though the observed increment in the deeper SOC was much lower $\left(0.36 \mathrm{Mg} \mathrm{ha}^{-1}\right.$ year $\left.^{-1}\right)$. A few quadrats showed decrement values (three out of 30 in zone I, one out of 20 in zone II) of SOC.

Quadrats with larger tree diversity and density showed higher SOC increment. Quadrats with tree species bearing larger leaves also showed greater SOC increments compared to trees with xeric leaves. In both zones, SOC increment was a fraction of $\mathrm{NPP}_{\text {wood }}$ increment. The ratio between mean SOC increment and mean increment in $\mathrm{NPP}_{\text {wood }}$ was 0.86 for zone I and 0.23 for zone II (Supplementary Table 1).

\section{Covariation of precipitation, tree species diversity and NPP ${ }_{\text {wood }}$ increment}

Quadrats with tagged trees were found to have 66 angiosperm species across zones I and II (Supplementary Table 2). Tree species diversity was 35 in zone I and 48 in zone II. Among these, 17 species were common to both zones, 18 were exclusive to zone I and 31 were exclusive to zone II. Shannon diversity index ( $H$ value) calculated for zone I and zone II was 2.71 and 3.18 respectively. The higher $H$ value in zone II indicates that relatively higher precipitation supports a larger number of tree species. Trees in zone I were shorter, smaller and more likely to have dissected leaves. Trees in zone II were taller, having broader leaves on a well-spread canopy. Among the species common to both zones, the economically important $T$. grandis L. f. and A. catechu Willd. had similar mass increment regardless of precipitation variability. In contrast, three other species (Butea monosperma, Acacia leucophloea, Diospirum melanoxylum) showed significantly larger values in zone II, while one (Anogeisus latifolia) in zone I (Figure 2). This is indicative of speciesspecific response in the increment of $\mathrm{NPP}_{\text {wood }}$ when exposed to precipitation variability.

Among species exclusively found at either zone, increment in $\mathrm{NPP}_{\text {wood }}$ was significantly (at $\mathrm{CI}_{95}$ ) higher (nearly twofold) in the species exclusive to zone II compared to those exclusive to zone I (Figure 3). Zone-specific species in zone I showed a mean annual increment of 0.54 $2.89 \mathrm{~kg} \mathrm{year}^{-1}$ in $\mathrm{NPP}_{\text {wood, }}$, while it ranged between 1.37 and $10.82 \mathrm{~kg} \mathrm{year}^{-1}$ in zone II. Mean annual $\mathrm{NPP}_{\text {wood }}$ increment values for the common species ranged from 0.54 to 3.79 and 1.56 to $3.71 \mathrm{~kg} \mathrm{year}^{-1}$ for zone I and zone II respectively.

Despite similarity in the values of basal area, quadrats with higher tree species diversity had $>53 \%(53-104 \%)$ significantly higher carbon stocks. Increment in $\mathrm{NPP}_{\text {wood }}$ was 0.20 and $0.37 \mathrm{Mg} \mathrm{ha}^{-1}$ year $^{-1}$ with one and three species respectively, in zone $\mathrm{I}$ while it was 0.71 and $3.71 \mathrm{Mg} \mathrm{ha}^{-1}$ year $^{-1}$ with two and eight species respectively, in zone II. To check increment in $\mathrm{NPP}_{\text {wood }}$ per unit wood mass $(10 \mathrm{~kg})$, trees with similar baseline mass range were pooled for analysis. We found common species in zone I and zone II showed 0.38 and $0.48 \mathrm{~kg}$ year $^{-1}$ mean increment in $\mathrm{NPP}_{\text {wood }}$ (per $10 \mathrm{~kg}$ of tree mass) respectively, while unique species showed 0.52 and $0.60 \mathrm{~kg}$ year ${ }^{-1}$ mean increment in $\mathrm{NPP}_{\text {wood }}$ (per $10 \mathrm{~kg}$ of tree mass) for zone I and zone II respectively. Inter-generic and intra-generic variations were seen in this increment (Figures 2 and 3, Supplementary Figure 8). 


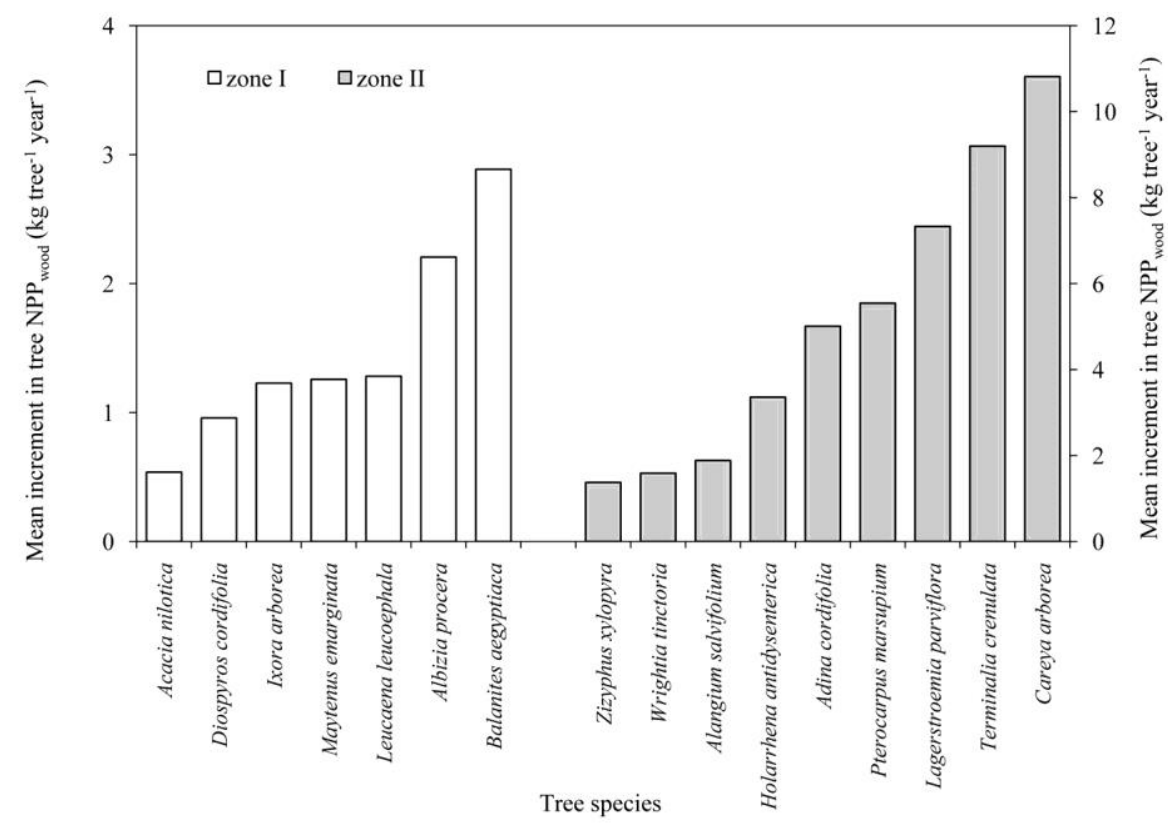

Figure 3. Mean increment in $\mathrm{NPP}_{\text {wood }}\left(\mathrm{kg} \mathrm{tree}^{-1}\right.$ year $^{-1}$, after a five-year timescale) amongst specific species to each zone.

\section{SIF values and their sensitivity towards precipitation variability}

Both inter- and intra-annual variations were distinct in SIF values across the study area (Figure 4; Supplementary Figures 9 and 10). Annual mean SIF values ranged between 0.92 and 1.42 as well as 1.49 and 1.95 for zone I and zone II respectively. Monthly mean SIF values showed linear correlation with monthly mean precipitation for zones I and II. Mean SIF values decreased by $21.1 \%$ (2009) and $12.2 \%$ (2012) in zone I and zone II respectively, when there was a nearly $50 \%$ decline in mean rainfall from the five-year mean values. The five-year timescale summed up SIF values ranged between 3.69 and 5.67 during 2009-2014 in zone I, while the values were higher in zone II (5.96-7.81). SIF values were consistent with satellite-derived NPP (Figure 4). Mean NPP found to be higher in zone II, which ranged between 0.94 and $1.13 \mathrm{gC} / \mathrm{m}^{2} /$ day. NPP values for zone I ranged between 0.75 and $0.88 \mathrm{gC} / \mathrm{m}^{2} /$ day (Figure 4; Supplementary Figure 11).

\section{Discussion}

\section{Variability in precipitation, SOC and tree growth}

Similar to the findings of Fensholt et $a l .{ }^{16}$, there was good correspondence between vegetation dynamics and precipitation across the present study area, showing a positive relationship between carbon stock and precipitation gradients. These results hold even though interannual variation in precipitation in the study region was higher than those reported elsewhere in similar regions, such as a semi-arid region in Spain ${ }^{17}$.

Observations indicate that precipitation augmented $\mathrm{NPP}_{\text {wood }}$ and SOC of semi-arid forests having relatively higher tree cover. Similar type of variation in the carbon balance of semi-arid and arid ecosystems of North America was reported by Huxman et al. ${ }^{18}$ due to differential impact of rainfall pulse on the activity of plants and microbes, and on vegetation and soils in SE Spain ${ }^{19}$. $\mathrm{NPP}_{\text {wood }}$ in high tree cover plots was 2-3 times greater to the ones reported for a ten-country network of long-term monitoring in the African tropical forests. This sustained high $\mathrm{NPP}_{\text {wood }}$ provides evidence that increasing carbon storage is more than a pan-tropical phenomenon ${ }^{20}$.

We also observed significant increase in SOC of both the zones I and II over the five-year timescale in most plots, consistent with other studies for semi-arid regions across India ${ }^{21}$. Changes in SOC reported here were also consistent with those of Tian et al. ${ }^{22}$ and Ahlstrom et $a{ }^{23}$. In particular, we found that high tree cover plots promoted soil storage in both shallow $(0-5 \mathrm{~cm})$ and deep $(10-15 \mathrm{~cm})$ soil. Zhou et al. $^{24}$ also reported that the top $20 \mathrm{~cm}$ soil layer of preserved old-growth tropical forests in southern China accumulated carbon at an unexpectedly high rate from 1979 to 2003.

Influence of tree cover fraction on NPP wood and SOC sensitivity to precipitation

Though precipitation explained the spatial patterns of species diversity and productivity, increments in NPP ${ }_{\text {wood }}$ and SOC were less sensitive to fluctuations in the 

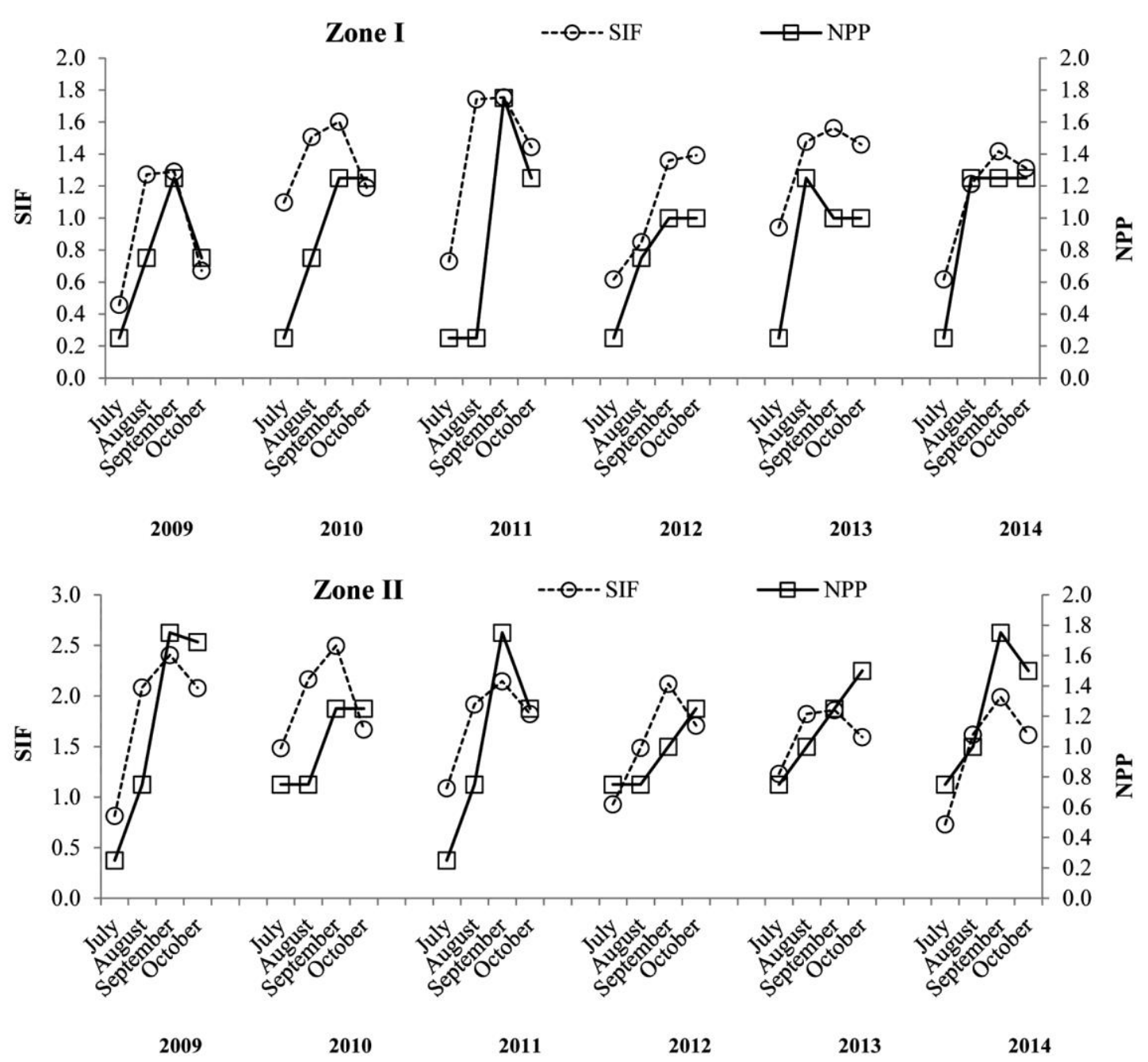

Figure 4. Inter- and intraannual variability in mean solar-induced fluorescence (SIF) and net primary productivity (NPP) values during monsoon months for zones I and II (2009-2014).

precipitation compared to those reported for tree covers of Amazonia ${ }^{25,26}$. Instead, the dominant temporal drivers of variations in $\mathrm{NPP}_{\text {wood }}$ and SOC were heterogeneity in tree cover, leaf size and longevity, and wood density. All study plots showed positive relationship of $\mathrm{NPP}_{\text {wood }}$ to spatial variation in tree-cover fraction, tree size and precipitation. This finding is consistent with that of Levine et $a{ }^{27}{ }^{27}$, who reported that biomass heterogeneity was the primary control on response of Amazonian forest productivity to dry season length.

Trees with larger trunk diameter showed greater increment (by 100-700\%), indicating that larger trees have the greatest growth potential in semi-arid regions. The predominant tree cover of zone I had smaller leaves with less longevity, indicating that most of the fixed carbon in sparse cover regions was accumulated in $\mathrm{NPP}_{\text {wood. }}$. These observations were consistent with those of Clark et $a .^{28}$ and Hofhansl et al. ${ }^{8}$ indicating enhanced wood production in semi-arid trees, thereby increasing carbon sequestration in less-productive tropical forests.
Increment in carbon stocks did occur after a five-year timescale, in spite of the study area being declared as the one falling in drought region in 2009, starting time of this study. It appears that tree cover did respond to these variabilities in precipitation as evident from the lack of variation in SIF after the drought year. This leads us to infer that at least in these semi-arid regions, response of trees towards precipitation is seen as event-specific rather than as a legacy effect reported to be prevalent in many dry ecosystems ${ }^{29,30}$. Similarly, tree mortality, owing to drought, in this five-year timescale was insignificant, and predominantly related to human tree felling $(<3 \%)$. Thus, we conclude that any climate or infestation-related tree mortality has not occurred over the five-year timescale in both the zones. The lack of natural tree mortality can be attributed to the relatively higher wood density values of the tree species in this study ${ }^{31}$. These species, through their consistent addition to carbon stocks (both NPP wood and SOC), suggest a potential form of community-level drought response that could serve as a benchmark for 
improving drought responses in global carbon cycle models ${ }^{32}$.

\section{Impact of tree diversity on the dynamics of NPP wood and SOC}

Across the plots, tree diversity lowered the impact of annual precipitation variability on both $\mathrm{NPP}_{\text {wood }}$ and SOC, regardless of tree cover fraction. Zone-specific trees showed higher increments in $\mathrm{NPP}_{\text {wood }}$ and SOC compared to common trees of both the zones, hinting at the localized adaptation of these species to the observed precipitation dynamics. T. grandis L.f. and A. catechu Willd. fared near equal at both zones. The wide range of precipitation $\left(300-1413 \mathrm{~mm}\right.$ ) had no impact on $\mathrm{NPP}_{\text {wood }}$ of these two species. This along with the quality of timber of these species have augmented the commercial importance of these species to local population. Foresters of this region periodically plant these species. They are suitable for plantation activities across semi-arid regions for wood production and medium to long-term carbon storage.

The DRYFLOR ${ }^{33}$ deciduous dry forest diversity study reported high levels of species turnover, high endemism with few species being shared among the floristic groups. Similarly, in the plots of zones I and II of this study, out of 66 tree species recorded only 17 were common and the rest were zone-specific, highlighting species turnover of these dry forest covers.

Our finding of higher tree diversity leading to greater increment of plot-level $\mathrm{NPP}_{\text {wood }}$ is in congruence with earlier reports ${ }^{34-38}$. This effect is observed even in the low tree cover plots. There is a co-association of precipitation and diversity, such that higher mean annual rainfall plots resulted in greater density and diversity of trees, and quadrats of zone II showed eight times more increment in $\mathrm{NPP}_{\text {wood }}$ over quadrats of zone I. These findings were also replicated at the plot level within zones.

Mechanisms that drive the observed relationship among precipitation, diversity, and $\mathrm{NPP}_{\text {wood }}$ increment can be attributed to relatively higher and diverse wood density values, variable leaf size and longevity. Previous studies have noted that variability in leaf traits and wood density had a significant impact on the growth of trees in drought-prone regions ${ }^{39,40}$, as these traits (wood density, leaf size, longevity) function on plant hydraulics ${ }^{41}$. It has been reported that dry forest phenological diversity is associated with divergent ecological strategies for dealing with seasonal moisture constraints ${ }^{42}$. Trees with low wood density can be more sensitive to drought ${ }^{43,44}$. Thus, greater variance in the species regarding the abovementioned traits can influence efficient utilization of available water, leading to adaptive capacity of dry forest species-diverse plant communities, making them less sensitive to precipitation with relatively higher absolute magnitude of $\mathrm{NPP}_{\text {wood. }}$

\section{Sensitivity of SIF values}

SIF has previously been shown to provide a novel stress indicator in many types of ecosystems ${ }^{45}$ with the potential for characterizing and monitoring the spatial and temporal dynamics of drought in vegetated regions ${ }^{46}$. The present analysis confirmed that SIF is a reliable proxy for spatial scaling of the relationship between $\mathrm{NPP}_{\text {wood }}$ and precipitation. The drought year of 2009 showed marked decrease in SIF. Similar to the tree cover control on NPPprecipitation response, the same variation in annual rainfall led to significantly larger impact in SIF of zone I compared to zone II, consistent with ground-based differences in the increment of $\mathrm{NPP}_{\text {wood }}$ of common tree species for both the zones. Sensitivity in the response of SIF values in this semi-arid region indicates the usefulness of SIF in modelling drought sensitivity of vegetation processes at quarterly or annual timescales.

\section{Uncertainty analysis}

All regression models developed between mass increment and tree mass, SIF and monthly precipitation, basal area and mass increment respectively, showed high $R^{2}$ values (0.68-0.89). The model used to calculate $\mathrm{NPP}_{\text {wood }}$ was from Chave et al. ${ }^{12}$, who showed an overestimation error of $2.7 \%$. The estimated SOC had an error of $5 \%$. Based on the regression coefficients regarding the relationship between the inputs and outputs, the maximum uncertainty in the computed estimates using the regression models would be lower than $2.5 \%$. Normal probability plots of the residuals developed for these regression models were linear, supporting the condition that the error terms are normally distributed. $\mathrm{NPP}_{\text {wood }}$ growth rates were modelled using pairwise regression, where the independent variable was divided into two bins. Conjoined line segments were placed together. Lines showed two growth models with relatively higher increments of growth at larger DBH of the trees (Supplementary Figure 7). The $t$-test (for comparing means of $\mathrm{NPP}_{\text {wood }}$, SOC, increment in $\mathrm{NPP}_{\text {wood }}$ in species exclusive to zones) showed that mean values were significantly different at $\mathrm{CI}_{95}$. As a result, the main findings here (i.e. evident impact of precipitation variation on above-ground tree biomass and SOC, effective modulation of existing tree diversity in response to precipitation variability and SIF dynamics in sync with variability in rainfall of these regions), appear robust to known sources of uncertainty in the analytical techniques.

\section{Conclusion}

Thus, semi-arid forests in India showed high resilience in productivity in response to variability in precipitation with consistently increased wood and soil carbon stock over a five-year timescale. A comparison of plot-level 
results to remote sensing also predicts a high likelihood for extrapolation from plot to region with remote sensingbased SIF.

The high investment in $\mathrm{NPP}_{\text {wood }}$ rather than on the leaves of canopy in low precipitation plots reflects an adaptive strategy of these trees in a water-limiting semiarid system. Plot-level measurements of Indian tropical forests are limited, preventing regional-wide extrapolation regarding NPP, SOC and carbon storage (both in tree biomass and SOC). The present findings contribute novel observations in an under-studied region to advance our understanding of how a positive carbon sink is maintained in sparse tree cover regions, in spite of high precipitation variability. Future work to scale these results across entire management units can assist regional federal agencies towards addressing carbon emission reporting requirements, and also in preparing for climate adaptation and mitigation strategies.

1. Poulter, B. et al., Contribution of semi-arid ecosystems to interannual variability of the global carbon cycle. Nature, 2014, 509, 600-604.

2. Malhi, Y. et al., Exploring the likelihood and mechanism of a climate-change-induced dieback of the Amazon rainforest. Proc. Natl. Acad. Sci. USA, 2009, 106(49), 20610-20615.

3. Rowland, L. et al., Death from drought in tropical forests is triggered by hydraulics not carbon starvation. Nature, 2015, 528, 119-122.

4. Doughty, C. E. et al., Drought impact on forest carbon dynamics and fluxes in Amazonia. Nature, 2015, 519, 78-82.

5. Liang, J. et al., Positive biodiversity-productivity relationship predominant in global forests. Science, 2016, 354(6309), 196.

6. Berdugo, M., Kéfi, S., Soliveres, S. and Maestre, F. T., Plant spatial patterns identify alternative ecosystem multifunctionality states in global drylands. Nature, 2017, 1(0003), 1-7.

7. Fauset, S. et al., Drought-induced shifts in the floristic and functional composition of tropical forests in Ghana. Ecol. Lett., 2012, 15, 1120-1129.

8. Hofhansl, F., Schnecker, J., Singer, G. and Wanek, W., New insights into mechanisms driving carbon allocation in tropical forests. New Phytol., 2015, 205, 137-146.

9. Guan, K. et al., Improving the monitoring of crop productivity using spaceborne solar-induced fluorescence. Global Change Biol., 2016, 22, 716-726.

10. Zhang, Y. et al., Consistency between sun-induced chlorophyll fluorescence and gross primary production of vegetation in North America. Remote Sensing Environ., 2016, 183, 154-169.

11. Mehta, N., Pandya, N. R., Thomas, V. O. and Krishnayya, N. S. $\mathrm{R}$., Impact of rainfall gradient on aboveground biomass and soil organic carbon dynamics of forest covers in Gujarat, India. Ecol. Res., 2014, 29, 2053-2063.

12. Chave, J. et al., Improved allometric models to estimate the aboveground biomass of tropical trees. Global Change Biol., 2015, 20, 3177-3190.

13. Chave, J. et al., Tree allometry and improved estimation of carbon stocks and balance in tropical forests. Oecologia, 2005, 145, 87-99.

14. Brown, S., Estimating biomass and biomass change of tropical forests: a primer. FAO Forestry Paper-134, Food and Agriculture Organization of the United Nations, Rome, Italy, 1997, ISBN: $92-$ 5-103955-0.

15. Walkley, A. and Black, I. A., An examination of the Degtjareff method for determining soil organic matter and proposed modifi- cations of the chromic acid titration method. Soil Sci., 1934, 37 29-38.

16. Fensholt, R. et al., Greenness in semi-arid areas across the globe 1981-2007 - an earth observing Satellite based analysis of trends and drivers. Remote Sensing Environ., 2012, 121, 144-158.

17. Lazaro, R., Rodrigo, F. S., Gutierrez, L., Domingo, F. and Puigdefabregas, J., Analysis of a 30-year rainfall record $(1967+1997)$ in semi-arid SE Spain for implications on vegetation. J. Arid Environ., 2001, 48, 373-395.

18. Huxman, T. E. et al., Precipitation pulses and carbon fluxes in semi-arid and arid ecosystems. Oecologia, 2004, 141, 254-268.

19. Domingo, F. et al., Carbon and water exchange in semi-arid ecosystems in SE Spain. J. Arid Environ., 2011, 75, 1271-1281.

20. Lewis, S. L. et al., Increasing carbon storage in intact African tropical forests. Nature, 2009, 457, 1003-1007.

21. Sreenivas, K. et al., Digital mapping of soil organic and inorganic carbon status in India. Geoderma, 2016, 269, 160-173.

22. Tian, H. et al., Effect of interannual climate variabilityon carbon storage in Amazonian ecosystems. Nature, 1998, 396, 664-667.

23. Ahlstrom, A. et al., The dominant role of semi-arid ecosystems in the trend and variability of the land $\mathrm{CO}_{2}$ sink. Science, 2015, 348(6237), 895-899.

24. Zhou, G. et al., Old-growth forests can accumulate carbon in soils. Science, 2006, 314, 1417.

25. Saatchi, S. et al., Persistent effects of a severe drought on Amazonian forest canopy. Proc. Natl. Acad. Sci. USA, 2013, 110(2), 565-570.

26. Brienen, R. J. W. et al., Long-term decline of the Amazon carbon sink. Nature, 2015, 519, 344-348.

27. Levine, N. M. et al., Ecosystem heterogeneity determines the ecological resilience of the Amazon to climate change. Proc. Natl. Acad. Sci. USA, 2016, 113(3), 793-797.

28. Clark, D. A. et al., Measuring net primary production in forests: concepts and field methods. Ecol. Appl., 2001, 11, 356-370.

29. Reichstein, M. et al., Climate extremes and the carbon cycle. Nature, 2013, 500, 287-295.

30. Anderegg, W. R. L. et al., Pervasive drought legacies in forest ecosystems and their implications for carbon cycle models. Science, 2015, 349(6247), 528-532.

31. Wright, S. J. et al., Functional traits and the growth-mortality trade-off in tropical trees. Ecology, 2010, 91(12), 3664-3674.

32. Hartmann, H. et al., Research frontiers in drought induced tree mortality: crossing scales and disciplines. New Phytol., 2015, 205, 965-969.

33. Banda, K. et al., Plant diversity patterns in neotropical dry forests and their conservation implications. Science, 2016, 353(6306), 1383-1387.

34. Lima, R. F., Olmos, F., Dallimer, M., Atkinson, P. W. and Barlow, J., Can REDD+ help the conservation of restricted-range island species? Insights from the endemism hotspot of Sao Tome. PLoS ONE, 2013, 8, e74148.

35. Bunker, D. E., Declerck, F., Bradford, J. C., Colwell, R. K., Perfecto, I., Phillips, O. L. and Naeem, S., Species loss and aboveground carbon storage in a tropical forest. Science, 2005, 310, 1029-1031.

36. Conti, G. and Diaz, S., Plant functional diversity and carbon storage: an empirical test in semi-arid forest ecosystems. J. Ecol., 2013, 101, 18-28.

37. Gilroy, J. J. et al., Cheap carbon and biodiversity cobenefits from forest regeneration in a hotspot of endemism. Nature Climate Change, 2014, 4, 503-507.

38. Bustamante, M. M. C. et al., Toward an integrated monitoring framework to assess the effects of tropical forest degradation and recovery on carbon stocks and biodiversity. Global Change Biol., 2016, 22, 92-19.

39. Chave, J. et al., Towards a worldwide wood economics spectrum. Ecol. Lett., 2009, 12, 351-366. 


\section{RESEARCH ARTICLES}

40. Wright, I. J. et al., The worldwide leaf economics spectrum. Nature, 2004, 428, 821-827.

41. Wright, I. J. et al., Relationships among ecologically importan dimensions of plant trait variation in seven neotropical forests. Ann. Bot., 2007, 99, 1003-1015.

42. Lasky, J. R., Uriarte, M. and Muscarella, R., Synchrony, compensatory dynamics, and the functional trait basis of phenological diversity in a tropical dry forest tree community: effects of rainfall seasonality. Environ. Res. Lett., 2016, 11, 115003.

43. McDowell, N. et al., Mechanisms of plant survival and mortality during drought: why do some plants survive while others succumb to drought? New Phytol., 2008, 178, 719-739.

44. Phillips, O. L. et al., Drought sensitivity of the Amazon rainforest. Science, 2009, 323, 1344-1347.

45. Guanter, L. et al., Global time-resolved monitoring of crop photosynthesis with chlorophyll fluorescence. Proc. Natl. Acad. Sci. USA, 2014, 111(4), E1327-E1333.
46. Sun, Y. et al., Drought onset mechanisms revealed by satellite solar-induced chlorophyll fluorescence: insights from two contrasting extreme events. J. Geophys. Res.: Biogeosci., 2015, 120(11), $1-14$

ACKNOWLEDGEMENTS. N.S.R.K. and N.M. thank National Remote Sensing Centre, Indian Space Research Organization, Hyderabad for financial assistance under Vegetation Carbon Pool, phase II study. We thank the Gujarat State Forest Department and also to Mr S. N. Tyagi (Chief Conservator of Forest) for help during field survey. We also thank Luis Guanter, Helmholtz Centre Potsdam German Centre for Geosciences (GFZ), Germany for sharing the SIF dataset.

Received 28 January 2019; revised accepted 4 August 2020

doi: $10.18520 / \mathrm{cs} / \mathrm{v} 119 / \mathrm{i} 9 / 1517-1525$ 